TEACHING TACTIC

\title{
Teaching Virtue Theory Experientially
}

\author{
Kent Eilers \\ Huntington University
}

\section{The context}

I teach in a Christian liberal arts setting and use this strategy with upper-level nursing and premed students in a course titled "Theological Bioethics," which is essentially a medical ethics class from a Christian, theological perspective.

\section{The pedagogical purpose}

A learning outcome for this course involves moral reasoning from a range of different ethical systems. Students must demonstrate proficiency in approaching ethical challenges from the standpoints of various approaches to morality, such as deontology, utilitarianism, and virtue theory. Specifically regarding virtue theory, I have found (over ten years) that students consistently and profoundly struggle to reason from this approach. They have no language for speaking virtue theory; no coordination for its dance steps; no way to see ethical deliberation from its vantage point. Rather than address the learning challenge theoretically, this tactic addresses it experientially.

\section{Description of the strategy}

The strategy consists of fourteen activities that reveal settled habits and generate embodied familiarity with virtue theory's approach. Called Formation Experiments (FEs), each centers on one of the seven Capital Virtues (humility, generosity, temperance, etc.) or seven Vices (vainglory, envy, gluttony, etc.). For instance, the FE on vainglory requires students to avoid their reflection, and then reflect on their management of appearance (an idea borrowed from DeYoung's Glittering Vices ${ }^{1}$ [2009]). The FE on humility requires students to ask questions in class or seek help from friends, and then reflect on their comfort with authenticity. An anger journal is required for the FE on wrath, in which students reflect on their anger's intensity and causes. And so on with the rest of the classic virtues and vices. One FE is assigned per week, lasts two days, and students may complete any ten. After completion of each FE, students reflect specifically on their experience through a one-page journal. Though I read each student's journal for specificity, I readily admit to them that I cannot verify their actual completion of the FE and point out the obvious fact: this is a character-oriented learning approach, and deception speaks volumes about theirs.

\section{Why it is effective}

To be clear, the tactic does not ask students to practice the vices (no!), nor do I suggest that two days of practicing virtue will form character. The wisdom of the ages, no less many in contemporary neuroscience and moral psychology, tell us the formation of character requires time and intention (Lewis [2012] $]^{2}$; Reilly and Narvaez [2018] $]^{3}$ ). Instead, FEs are diagnostic activities. They reveal one's settled habits, and-the learning payoff-they also generate experiential familiarity with virtue theory's approach. The strategy moves students past theoretical knowledge of virtue theory into realms of experiential understanding and transference. By practicing and then reflecting on activities that reveal character, students develop embodied familiarity with virtue theory's approach to moral reasoning - they gain some coordination with its dance steps, they learn to see from its vantage point. This experiential understanding enables them to apply virtue theory more fluently to the ethical scenarios we address in class discussions, written projects, and group work.

1 http://www.bakerpublishinggroup.com/books/glittering-vices/227920

2 https://doi.org/10.1080/03057240.2012.668005

3 https://doi.org/10.1628/ptsc-2018-0005 